\title{
A community-based study: Prevalence of diabetes mellitus and its complications in rural population of Moradabad district, Uttar Pradesh, India
}

\author{
Dubey P. ${ }^{1}$, Lal Bhantia B. ${ }^{2 *}$, Singh Yadav S. ${ }^{3}$ \\ DOI: https://doi.org/10.17511/ijphr.2019.i6.04 \\ 1 Prashant Dubey, Assistant Professor, Department of General Medicine, Teerthanker Mahaveer Medical College, Moradabad, Uttar Pradesh, \\ India. \\ 2* Bajrang Lal Bhantia, Associate Professor, Department of Medicine, Teerthanker Mahaveer Medical College, Moradabad, Uttar Pradesh, \\ India. \\ 3 Sachin Singh Yadav, Associate Professor, Department of Community Medicine, Teerthanker Mahaveer Medical College, Moradabad, Uttar \\ Pradesh, India.
}

Background: In last two-decade prevalence of Diabetes Mellitus in India is increasing at higher rate and currently India is the Diabetic Capital of the World. Reliable and informative epidemiological evidence is vital to quantify impacts and predictors of disease and to facilitate formulation of prevention and control strategies. In North India particularly Uttar Pradesh the area specific data regarding diabetes mellitus is scarce. Objectives: Prevalence of Type-II Diabetes Mellitus and its associated risk factors in rural population of the Moradabad district. Materials and Methods: ;A Cross-sectional, community-based study was conducted from October 2016 to October 2017 among adults in the age group of 30 year and above residing in Moradabad rural area. A two-stage stratified random sampling technique was adopted to achieve the desired sample size. Result: The prevalence of Diabetes Mellitus was found to be $10.7 \%$, it was $17.8 \%$ among males and $14.8 \%$ among females. $4.6 \%$ were newly diagnosed while the remaining $6.1 \%$ were known diabetics. In the present study statistically, significant association is observed between prevalence of diabetes mellitus with age, socioeconomic class, BMI. Conclusion: There is a need for continuous screening program and lifestyle modifications to timely detect and intervene in the pathogenesis of diabetes mellitus. Behaviour change communication strategy should take a vital role in improving lifestyle of the community as most of these risk factors are modifiable.

Keywords: Diabetes Mellitus, Impaired Fasting Glucose, Body Mass Index

Corresponding Author

Bajrang Lal Bhantia, Associate Professor, Department of Medicine, Teerthanker Mahaveer Medical College, Moradabad, Uttar Pradesh, India. Email: dr.blbanthia1852@gmail.com

\section{How to Cite this Article}

Dubey P, Bhantia BL, Yadav SS. A community-based study: Prevalence of diabetes mellitus and its complications in rural population of Moradabad district, Uttar Pradesh, India. Public Health Rev Int J Public Health Res. 2020;6(6):234-238. Available From https://publichealth.medresearch.in/index.php/ijphr/ article/view/126
To Browse

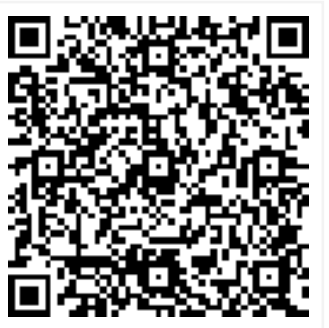

Manuscript Received 2019-12-24

Conflict of Interest No

Review Round 1
2019-12-04
Funding
Nil

Review Round 1 $\mathrm{Nil}$

Review Round 2
$2019-12-10$
Ethical Approval
Yes

Review Round 2

Yes
Review Round 3

Plagiarism X-checker $7 \%$
Accepted 2019-12-14

(c) 2020 by Prashant Dubey, Bajrang Lal Bhantia, Sachin Singh Yadav and Published by Siddharth Health Research and Socia Welfare Society. This is an Open Access article licensed under a Creative Commons Attribution 4.0 International License https://creativecommons.org/licenses/by/4.0/ unported [CC BY 4.0]. 


\section{Introduction}

India leads the world with largest number of diabetic subjects coming with the dubious distinction of being termed the "Diabetic capital of the world". The prevalence of Diabetes is rapidly rising all over the globe at an alarming rate [1] over the past 30 years the status of diabetics mellitus has changed from being considered as a mild disorder of the elderly to one of the major cause of mortality and morbidity affecting the youth and middle age people.

Nowhere is diabetic epidemic more pronounced than in India as WHO report shows that 32 million people had diabetics mellitus in 2000 [2] had diabetes mellitus and the estimate for year 2025 is 69 million [3].

\section{Aims and Objectives}

To study the prevalence of diabetes Mellitus in Rural population of Moradabad and to study the prevalence of complications of diabetes, retinopathy and nephropathy.

\section{Material and Method}

Duration: The study was done from October 2016 to October 2017.

Setting: The present study selected few villages of a selected rural block of Moradabad District and all individual more than 30 years of age willing to participate in the study were included in the study. It was a cross-sectional observational study.

Sample size: Sample size was calculated using the formula

- $N=(1.96) \wedge 2 P Q / D^{\wedge} 2$

- $\mathrm{P}=$ Prevalence

- $\mathrm{Q}=1-\mathrm{P}$

- $\mathrm{D}=$ error- $15 \%$

- $95 \%$ Confidence level

- $10 \%$ Non-response error,

Using the above formula and the demographic profile of the area a total of 800 cases were included.

Inclusion criteria: All individual more than 30 years of age willing to participate in the study and individuals with Type II Diabetes where included in the study.
Exclusion criteria: Individual who were excluded from the study where individuals less than 30 years of age, individuals with type I diabetes, individuals with gestational Diabetes.

Data collection technique and tool: The study was divided into 2 phases. Phase-I: All individuals in study underwent FBS (fasting blood sugar test). Those having fasting blood sugar $>126 \mathrm{mg} / \mathrm{dl}$ were eligible to participate in Phase-II of the study.

Capillary blood was taken, and glucometer was used for measuring fasting blood sugar. Phase-II: Those individual test positive in phase-I were screened for evidence of retinopathy and nephropathy by basic screening test.

Screening test used was for retinopathy by fundus examination using a fundoscope, for nephropathy by presence of albumin in 24-hour urine albumin test.

Data collected was evaluated using SSPS software (version 6). Chi Square test was used to study the correlation between various variables.

\section{Results}

Table-1: Distribution of cases according to fasting blood sugar status of study subjects.

\begin{tabular}{|l|l|l|l|l|l|l|l|}
\hline \multicolumn{2}{|c|}{ Known Diabetics } & \multicolumn{2}{|c|}{ Newly diagnosed } & \multicolumn{2}{c|}{ IFG } & \multicolumn{2}{c|}{ Normal } \\
\hline No. & $\%$ & No. & $\%$ & No. & $\%$ & No. & $\%$ \\
\hline 49 & $6.1 \%$ & 37 & $4.6 \%$ & 45 & $5.6 \%$ & 669 & $83.6 \%$ \\
\hline
\end{tabular}

Table-2: Distribution of diabetics and IFG study subjects according to socioeconomic status.

\begin{tabular}{|l|l|l|l|l|l|l|}
\hline \multicolumn{1}{|c|}{ Class } & \multicolumn{1}{|c|}{ Total no. } & \multicolumn{2}{|c|}{ Diabetics } & \multicolumn{2}{|c|}{ IFG } & \multirow{2}{*}{ p value } \\
\hline I & 96 & 16 & $16.6 \%$ & 7 & $7.2 \%$ & \\
II & 192 & 30 & $15.6 \%$ & 13 & $6.7 \%$ & \multirow{2}{*}{0.01} \\
III & 200 & 22 & $11 \%$ & 11 & $5.5 \%$ & \\
IV & 272 & 15 & $5.5 \%$ & 12 & $4.4 \%$ & \\
V V & 40 & 3 & $7.5 \%$ & 2 & $5 \%$ & \\
\hline
\end{tabular}

Table 2 demonstrated that the prevalence of Diabetes is $16.6 \%$ in Class I of BJ Prasad classification. The prevalence decreases to $15.6 \%$ in class II. There is further decline in prevalence to $11 \%$ in Class III and $5.5 \%$ in Class IV.

There is increase in the prevalence to $7.5 \%$ in Class V. On applying Chi square test the $p$ value was 0.01 which shows that there is statistically significant correlation between socioeconomic status and Diabetes. 
Similar trend is seen on correlating socioeconomic status and IFG [4].

\section{Table-3: Distribution of Diabetics according to} BMI

\begin{tabular}{|l|l|l|l|l|l|l|}
\hline \multirow{2}{*}{ BMI } & \multirow{2}{*}{ Total } & \multicolumn{2}{|c|}{ Diabetes } & \multicolumn{2}{c|}{ IFG } & \multirow{2}{*}{ P value } \\
\cline { 3 - 6 } & & No. & $\%$ & No. & $\%$ & \\
\hline$<18.5$ & 110 & 6 & $5.4 \%$ & 4 & $3.6 \%$ & \\
\hline $18.5-24.9$ & 486 & 36 & $7.4 \%$ & 19 & $3.9 \%$ & \multirow{2}{*}{0.001} \\
\hline $25-29.9$ & 135 & 24 & $17.7 \%$ & 13 & $9.6 \%$ & \\
\hline $30-34.9$ & 44 & 12 & $27.2 \%$ & 6 & $13.6 \%$ & \\
\hline$>=35$ & 25 & 8 & $32 \%$ & 3 & $12 \%$ & \\
\hline
\end{tabular}

On applying chi square test the $p$ value comes out to be 0.001 which shows that there is statistically significant correlation between BMI and Diabetes in the study.

Table-4: Prevalence of retinopathy in diabetics

\begin{tabular}{|l|l|l|}
\hline $\begin{array}{c}\text { Total no. of } \\
\text { diabetics }\end{array}$ & $\begin{array}{c}\text { No. of diabetics having } \\
\text { retinopathy }\end{array}$ & $\begin{array}{c}\% \text { of diabetics having } \\
\text { retinopathy }\end{array}$ \\
\hline 86 & 13 & $15.1 \%$ \\
\hline
\end{tabular}

Table 4 demonstrated that among 86 diabetics 13 of them had retinopathy (15.1\%).

Table-5: Prevalence of nephropathy in diabetics.

\begin{tabular}{|l|l|l|}
\hline $\begin{array}{c}\text { Total No. of } \\
\text { diabetics }\end{array}$ & $\begin{array}{c}\text { No. of diabetics having } \\
\text { nephropathy }\end{array}$ & $\begin{array}{c}\% \text { of diabetics having } \\
\text { nephropathy }\end{array}$ \\
\hline 86 & 19 & $22.1 \%$ \\
\hline
\end{tabular}

Table 5 showed that out of 86 diabetics 19 diabetics had evidence of nephropathy ( $22.1 \%)$.

\section{Table-6: Correlation between Diabetic Retinopathy and Nephropathy}

\begin{tabular}{|c|c|c|c|}
\hline $\begin{array}{c}\text { No. of individuals } \\
\text { having } \\
\text { alone }\end{array}$ & $\begin{array}{c}\text { No. of individuals } \\
\text { having } \\
\text { Nephropathy } \\
\text { alone }\end{array}$ & $\begin{array}{c}\text { No. of individuals } \\
\text { having both } \\
\text { Nephropathy and } \\
\text { Retinopathy }\end{array}$ & $\begin{array}{c}\mathrm{p} \\
\text { value }\end{array}$ \\
\hline 6 & 12 & 7 & \\
\hline
\end{tabular}

Table 6 demonstrated correlation of nephropathy and retinopathy. The cases of diabetes in the study who had nephropathy alone were 12 and those with retinopathy alone were 6 . The diabetics who had presence of both retinopathy and nephropathy were 7.

The $p$ value on applying chi square test was 0.001 which shows that there is a statistically significant correlation between Nephropathy and retinopathy. This shows that patients who have diabetic nephropathy are more prone to develop retinopathy and vice versa [5].

\section{Discussion}

Total 800 cases were included in the study and their fasting blood sugar was estimated. The cases who were diabetics were examined for presence of nephropathy and retinopathy. In the present study the overall prevalence of Diabetes was $10.7 \%$ amongst which newly diagnosed cases were $4.6 \%$ and known diabetics were $6.1 \%$.

The prevalence of IFG in the present study was $5.6 \%$. A study conducted by G Vijay Kumar et al (2008) among 1990 adults (women 1149, men 841) of two panchayat wards in Venmony Panchayat, Chengannur, Kerala, India.

Those who were on drugs for diabetes mellitus and or having fasting plasma glucose (FBS $>=126 \mathrm{mg} / \mathrm{dl}$ were considered as diabetes mellitus, those with FBS $100-125 \mathrm{mg} / \mathrm{dl}$ was considered impaired fasting glucose. The crude age adjusted prevalence of diabetes mellitus was $14.6 \%$ and $12.6 \%$ and that of IFG was $5.1 \%$ and $4.6 \%$ [6].

In the present study there is increasing prevalence of diabetes with age $6.7 \%$ in $30-40$ years, $10.3 \%$ in 40-50 years, $12.5 \%$ in $50-60$ years with further increase to $16.9 \%$ in $60-70$ years. There is a decline in the prevalence of diabetes to9.3\% in individuals of more than 70 years but this correlation of diabetes with age has no statistically significance.

Similar trend of increasing prevalence up to 70 years of age and decline thereafter was also observed by $V$ Mohan et al. (CURES), Ramachandran A et al (NUDS) and R. M. Anjana et al. $(2011)[7,8,9]$.

In the present study the prevalence of Diabetes is $16.6 \%$ in Class I of BJ Prasad classification. The prevalence decreases to $15.6 \%$ in class II. There is further decline in prevalence to $11 \%$ in Class III and $5.5 \%$ in Class IV, the prevalence is $7.5 \%$ in Class V.

The correlation of diabetes with socioeconomic status has statistically significant correlation in the present study. In the present study, that there was a statistically significant correlation between diabetes and BMI i.e. there is increasing trend of diabetes with increasing BMI.

Bhatti JS et al had also observed that the north Indian diabetic patients had a pronounced abdominal obesity as evidenced by their significant higher waist circumference and higher WHR [10]. Similarly, Ravikumar P et al. (2010) also reported 
That the abdominal obesity was significantly and positively associated with diabetes mellitus [11].

In the present study $15.1 \%$ of the diabetics showed evidence of retinopathy. The CURES study conducted by Ramchandran et al in Chennai shows prevalence of retinopathy in diabetics to be $17.6 \%$ which is slightly higher than our present study [12]. Rema et al in their study mentioned a prevalence of $7.8 \%$ retinopathy in diabetic patients [13]. The present study shows that the prevalence of retinopathy among diabetics was slightly more among males (16.6\%) as compared to females (13.1\%).

In the present study the prevalence of nephropathy among diabetics was $22.1 \%$. A study conducted by Vaibhav Shukla et al in Lucknow shows a lower prevalence $(19 \%)$ of nephropathy compared to the present study [14]. Gupta et al reported a prevalence of $26.6 \%$ in 65 type 2 diabetics of North India.

In the present study $25 \%$ of the male diabetics had nephropathy while the prevalence of nephropathy among female diabetics was comparatively less i.e. $18.4 \%$. In the present study it was observed that majority of the diabetics $(77.9 \%)$ had no albuminuria, $13.9 \%$ had evidence of micro albuminuria while only $8.1 \%$ of the diabetics had macro proteinuria and this correlation is statistically significant.

There was significant correlation between diabetic retinopathy and nephropathy [15].

\section{Conclusion}

Prevalence of Diabetes Mellitus among adult population of Moradabad rural area is as high as many urban cities of India and half of the diabetics are unaware of their diabetic status. Due to this wide diagnostic gap, preventable complications and avoidable morbidities related to diabetes mellitus are on a steep rise thus, further adding to the heavy disease burden.

There is a need of continuous screening program as a part of health care delivery system to timely detect and intervene in the pathogenesis of diabetes and related morbidities. Life style modifications from early age, with regard to physical activity, especially for individuals with family history of diabetes should be implemented, so that the occurrence of diabetes can be prevented or at least postponed [9].

\section{What the study adds to the existing knowledge}

The present study generated an area specific data on diabetes mellitus in rural population of Moradabad. The present study shows as an overall prevalence of $10.7 \%$ amongst which newly diagnosed cases were $4.6 \%$ and known diabetics were $6.1 \%$. A very few studies have been conducted in this region, this will further help us to understand the demography of Diabetes Mellitus in this region. The prevalence of impaired glucose tolerance is $5.6 \%$ in the rural community.

A proper awareness program is needed regarding Diabetes Mellitus so that these people may be prevented from overt DM. The present study showed a significant correlation between the complications of Diabetes Mellitus i.e. retinopathy with nephropathy. The prevalence of retinopathy (15.1\%), nephropathy (22.1\%) was quite high. So, the present study concluded that patient of Diabetes Mellitus should be screened for these complications regularly.

\section{Author's contribution}

Dr. Prashant Dubey: Data collection tabulation \& formulation of the paper.

Dr. B. L. Bhantia: Guidance.

Dr. S. S. Yadav: Application of statistic and formation of Tables.

\section{Reference}

01. Huizinga MM, Rothman RL. Addressing the diabetes pandemic- A comprehensive approach. Indian J Med Res. 2006;124(5)481-484.

[Crossref]

02. Wild S, Roglic G, Green A, Sicree R, King N. Global prevalence of diabetes, Estimate for year 2000 and projection for 2030. Diabetes Care. 2004;27(5)1047-1053. doi: [Article] [Crossref]

03. Whiting DR, Guariguata L, Weil C, Shaw J. IDF Diabetes Atlas- Global estimates of the prevalence of diabetes for 2011 and 2030. Diabetes Research and Clinical Practice. 2011; 94(3)311-321.

doi: $\quad 10.1016 /$ j.diabres.2011.10.029. [Crossref] 
04. Yang W, Lu J, Weng J, Jia W, Ji L, Xiao J et al. Pr evalence of diabetes among man and women in China. N Engl J Med. 2010;362(12)1090-1101. doi: 10.1056/NEJMoa0908292 [Crossref]

05. Chandy A, Pawar B, John M, Isaac R. Association between diabetic nephropathy and other micro and macrovascular complications. Saudi J Kidney Dis Transpl. 2008;16(6)924-928. [Crossref]

06. Kumar GV, Arun R, Kutty VR. High prevelance of type 2 diabetes mellitus and other metabolic disorders in rural central kerela. J Associate Physian of India. 2009;57(8)563-567.

[Crossref]

07. Mohan V, Deepa M, Deepa R, Shanthirani CS, Farooq S, Ganesan A, et al. Secular trends in the prevalence of diabetes and glucose tolerance in urban South India-the Chennai Urban Rural Epidemiology Study (CURES-17). Diabetologia. 2006;49(6)1175-1178.

doi: $\quad 10.1007 / \mathrm{s} 00125-006-0219-2 \quad$ [Crossref]

08. Ramachandran A, Snehalatha C, Kapur A, Vijay $V$, Mohan V, Das AK. High prevalence of diabetes and impaired glucose tolerance in India, National Urban Diabetes Survey. Diabetologia. 2001;44(9)1094-1101.

doi: [Article] [Crossref]

09. Anjana RM, Ali MK, Pradeepa R, Deepa M, Datta $M$, Unnikrishnan $R$. The need for obtaining accurate nationwide estimates of diabetes prevalence in India - Rationale for a national study on diabetes. Indian J Med Res. 2011;133(4)369-363.

[Crossref]

10. Bhatti JS, Bhatti GK, Joshi A. Identification of the risk factors for the high prevalence of type 2 diabetes and its complications in a Punjabi population, North Indian Diabetes Study- A case-control study. Int J Diab Develop Count. 2007;27(4)108-115.

doi: $10.4103 / 0973-3930.38629$ [Crossref]

11. Ravikumar P, Bhansali A, Ravikiran M, Bhansali S. Prevalence and risk factors of diabetes in a community-based study in North India, the Chandigarh Urban Diabetes Study (CUDS). Diabetes Metab. 2011;37(3)216-221.

doi: $10.1016 /$ j.diabet.2010.10.004. [Crossref]
12. Ramachandran R, Anndakumar A. Prevalence and risk factors for diabetic retinopathy in Asian Indians with young onset Type 1 and Type 2 Diabetes. J Diab its Complicat. 2014;28 (3)291297.

doi: 10.1016/j.jdiacomp.2013.12.008. Epub 2014 Jan 6 [Crossref]

13. Rema M, Deepa R, Mohan V. Prevalence of retinopathy at diagnosis among Type 2 diabetic patients attending a diabetic centre in South India. $\mathrm{Br}$ J Ophthalmol. 2000; 84(9)1058-1060. doi: $10.1136 /$ bjo.84.9.1058 [Crossref]

14. Vaibhav S, Ritu K. A study of type 2 diabetes mellitus from rural areas. J Associate Phys India. 2014;62(8)682-684.

[Crossref]

15. Agrawal RP, Sharma P, Pal M, Kochar A, Kochar DK. Magnitude of dyslipedemia and its association with micro and macro vascular complications in type 2 diabetes- A hospitalbased study from Bikaner (Northwest India). Diab Res Clinic Prac. 2006;73(2)211-214. doi: 01.006 [Article] [Crossref] 